\section{International Scientific Journal Theoretical \& Applied Science}

Farida Arif Akperova Doctoral student of Institute of Agriculture Research under the Ministry of Agriculture of the Azerbaijan Republic nauka-xxi@mail.ru

Year: 2017 Issue: 08 Volume: 52

Published: $30.08 .2017 \quad$ http://T-Science.org

SECTION 31. Economic research, finance, innovation, risk management.

\title{
STUDY THE POSSIBILITY OF USING PERSIMMON DOSHAB IN THE PRODUCTION OF BAKERY PRODUCTS
}

\begin{abstract}
The possibility of using persimmon doshab in the production of bakery products is investigated in this article. Indicators of quality of grain grades of bread wheat Azametli 95 and Qirmizi Gul are analyzed. Recipes wheat bread mold is considered in brew method. Bakery quality of grain without adding, and then with the addition of persimmon doshab are researched too. Detail indicators such as the acidity of the bread with the addition of persimmon doshab, as well as increase bread laced with compared with the standard are shown in the article. Further evaluated the beneficial properties of Japanese persimmon for use as an additive in the production of bread and bakery products are given also.

Research has shown that good performance was distinguished by the sample bread with the addition of 5\% persimmon doshab. The expediency of additives in baking bread and bakery products with the aim of improving the quality of bread for the population living in regions with unfavorable environmental conditions, etc. are explained in the end of the article.

Key words: bakery goods, natural supplements, baking properties of grain, soft wheat grades, methods of dough preparation, preparation of bakery products, properties of bakery products with additives.

Language: Russian

Citation: Akperova FA (2017) STUDY THE POSSIBILITY OF USING PERSIMMON DOSHAB IN THE PRODUCTION OF BAKERY PRODUCTS. ISJ Theoretical \& Applied Science, 08 (52): 61-66.

Soi: http://s-o-i.org/1.1/TAS-08-52-9 Doi: crossef https://dx.doi.org/10.15863/TAS.2017.08.52.9
\end{abstract}

\section{ИССЛЕДОВАНИЕ ВОЗМОЖНОСТЕЙ ИСПОЛЬЗОВАНИЯ ДОШАБА ИЗ ХУРМЫ В ПРОИЗВОДСТВЕ ХЛЕБОБУЛОЧНЫХ ИЗДЕЛИЙ}

Аннотация: В статье исследована возможность использования дошаба из хурмы в производстве хлебобулочных изделий. Анализированы показатели качества зерна сортов мягкой пшеницы Азаметли 95 и Гырмызы гюль. Рассмотрена рецептура формового пшеничного хлеба опарным способом. Исследованы хлебопекарные качества зерна сначала без добавления, а далее с добавлением дошаба из хурмы. Подробно рассмотрены такие показатели как кислотность хлеба с добавлением дошаба из хурмы, а также показатели увеличения объема хлеба с добавкой по сравнению со стандартом. Далее оценены полезные свойства хурмы японской для использования в качестве добавки при производстве хлеба и хлебобулочных изделий.

Результаты исследований показали, что хорошими показателями отличалась проба хлеба с добавлением $5 \%$ дошаба из хурмы. В коние статьи обоснована ичелесообразность добавок при выпечке хлеба и хлебобулочных изделий с иелью улучшения качества хлеба для населения, проживающему в регионах с неблагополучной экологической обстановкой и др.

Ключевые слова: хлебобулочные изделия, натуральные добавки, хлебопекарные свойства зерна, сорта мягкой пшениць, способы приготовления теста, стадии приготовления хлебобулочных изделий, свойства хлебобулочных изделий с добавками.

\section{Introduction}

Хлеб - один из наиболее употребляемых населением продуктов питания. Хлебопекарные свойства зерна исследуемых сортов (Азаметли-95 и Гырмызы гюль-1) различны. Как видно из таблицы все показатели второго образца выше показателей первого. 


\begin{tabular}{l|lr|ll|ll} 
& ISRA (India) & $=\mathbf{1 . 3 4 4}$ & SIS (USA) & $=\mathbf{0 . 9 1 2}$ & ICV (Poland) & $=\mathbf{6 . 6 3 0}$ \\
Impact Factor: & ISI (Dubai, UAE) $=\mathbf{0 . 8 2 9}$ & PUHЦ (Russia) $=\mathbf{0 . 2 0 7}$ & PIF (India) & $=\mathbf{1 . 9 4 0}$ \\
& GIF (Australia) & $\mathbf{0 . 5 6 4}$ & ESJI (KZ) & $=\mathbf{3 . 8 6 0}$ & IBI (India) & $\mathbf{= 4 . 2 6 0}$ \\
& JIF & $=\mathbf{1 . 5 0 0}$ & SJIF (Morocco) & $\mathbf{2 . 0 3 1}$ & & \\
\hline
\end{tabular}

Показатели качества зерна сортов мягкой пшеницы АзНИИ Земледелия

Таблица 1.

\begin{tabular}{|c|c|c|c|c|c|c|c|c|}
\hline$\frac{\pi}{\tilde{\theta}}$ & 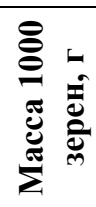 & 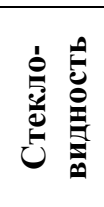 & 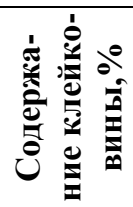 & 当 & 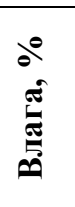 & 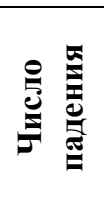 & 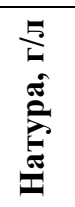 & 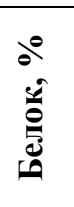 \\
\hline Азаметли - 95 & 30 & 46,0 & 28,0 & 77,8 & 13,2 & 265 & 760 & 13,0 \\
\hline Гырмызы гюль-1 & 36,1 & 46,5 & 30,0 & 79 & 13,7 & 334 & 788 & 12,4 \\
\hline
\end{tabular}

Materials and Methods

В последние годы большое внимание уделяется обогащению хлеба различными полезными растительными добавками. Введение рецептуру компонентов, придающих лечебные и профилактические свойства, позволяет решить проблему профилактики и лечения различных заболеваний, связанных с дефицитом тех или иных веществ. Первоочередным направлением в профилактике заболеваемости является укрепление иммунной системы.

Одним из путей решения этой проблемы, является использование экологически безопасных, нетрадиционных сырьевых ресурсов растительного происхождения. Значительный интерес представляет для нас введение их в состав традиционных пищевых продуктов, в частности в хлебобулочном производстве, и создание на их основе продуктов для детского, диетического питания и других групп населения, испытывающих нехватку витаминов [1]. В качестве перспективных ингредиентов для создания функциональных пищевых продуктов практический интерес представляют продукты переработки нетрадиционного растительного сырья, а именно дошаб из японской хурмы.
В Научно-Исследовательском Институте Земледелия нами проводились исследования возможностей использования натуральных добавок в производстве хлебобулочных изделий. Целью изобретения является разработка массовых сортов хлебобулочных изделий с выраженной иммунотропной активностью, используемого для профилактики ряда заболеваний, в том числе предраковых [2]. При этом изделия должны обладать хорошими вкусовыми и потребительскими свойствами, иметь привлекательный внешний вид. Получаемые изделия должны быть доступны по цене широким слоям населения [3].

Поставленная цель достигается тем, что в способе производства хлебобулочных изделий профилактической направленности, включающем приготовление опары и теста из муки, воды, соли с внесением растительного сырья, брожение, формование, расстойку тестовых заготовок и выпечку хлеба, согласно изобретению в качестве растительного сырья используют дошаб из японской хурмы.

Рецептура формового пшеничного хлеба

Таблица 2.

\begin{tabular}{|l|l|}
\hline Ингредиенты & Количество \\
\hline Мука пшеничная & 100,0 г \\
\hline Дрожжи хлебопекарные & 1,5 г \\
\hline Соль поваренная & 1,5 г \\
\hline Сахар & 4,0 г \\
\hline Добавки & $5-15 \%$ \\
\hline Вода & По расчёту \\
\hline
\end{tabular}

Этот способ приготовления хлеба является основным. Однако он менее экономичен и длителен (общая продолжительность приготовления хлеба - 6-8 часов); требует много рабочей силы, большая трудоёмкость, большее количество операций по дозировке и замесу, приводит к довольно большому расходу на брожение сухих веществ и т.д. Но решающее его преимущество более высокое качество хлеба и большая технологическая гибкость [4]. 


\begin{tabular}{l|lr|ll|ll} 
& ISRA (India) & $=\mathbf{1 . 3 4 4}$ & SIS (USA) & $=\mathbf{0 . 9 1 2}$ & ICV (Poland) & $=\mathbf{6 . 6 3 0}$ \\
Impact Factor: & ISI (Dubai, UAE) $=\mathbf{0 . 8 2 9}$ & PUHЦ (Russia) $=\mathbf{0 . 2 0 7}$ & PIF (India) & $=\mathbf{1 . 9 4 0}$ \\
& GIF (Australia) & $\mathbf{0 . 5 6 4}$ & ESJI (KZ) & $=3.860$ & IBI (India) & $=\mathbf{4 . 2 6 0}$ \\
& JIF & $=\mathbf{1 . 5 0 0}$ & SJIF (Morocco) & $=\mathbf{2 . 0 3 1}$ & & \\
\hline
\end{tabular}

Режим приготовления теста опарным способом

Таблица 3.

\begin{tabular}{|l|l|l|}
\hline \multicolumn{1}{|c|}{ Наименование сырья и показателей процесса } & \multicolumn{2}{c|}{ Расход сырья и параметры процесса } \\
\cline { 2 - 3 } & \multicolumn{1}{|c|}{ опара } & \multicolumn{1}{c|}{ тесто } \\
\hline Мука пшеничная (Азаметли-95, Гырмызы Гюль), г & 1,5 & 100 \\
\hline Дрожжи, г & & 1,5 \\
\hline Соль поваренная пищевая, г & 60 & \\
\hline Вода & 4 & $5-15$ \\
\hline Сахар, г & & $25-33$ \\
\hline Натуральные добавки, мл & $25-33$ & 120 и 60 \\
\hline Температура брожения, 0 С & 60 & 15 \\
\hline Продолжительность брожения, мин & & 5 \\
\hline Замес, мин & & $12-20$ \\
\hline Обминка, мин & & $212-220$ \\
\hline Выпечка, мин & & 20 \\
\hline Выпечка, 0 С & & \\
\hline Охлаждение, мин & & \\
\hline
\end{tabular}

У готовых формовых хлебцов мы произвели органолептическую оценку по стандарту на простой хлеб данных сортов муки (без добавок).

Таблица 4.

Хлебопекарные качества зерна

\begin{tabular}{|c|c|c|c|c|c|c|c|c|c|}
\hline \multirow{2}{*}{$\begin{array}{l}\tilde{\sigma} \\
\tilde{\partial} \\
\tilde{\partial}\end{array}$} & \multirow{2}{*}{ 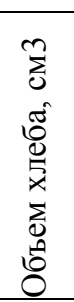 } & 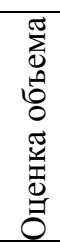 & 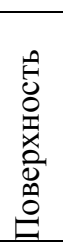 & $\begin{array}{l}\frac{\pi}{2} \\
\hat{0} \\
\hat{\theta}\end{array}$ & 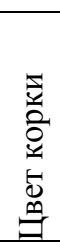 & 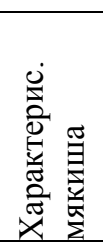 & $\begin{array}{l}\stackrel{0}{0} \\
0 \\
0 \\
0 \\
0 \\
0 \\
0\end{array}$ & 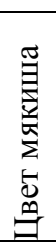 & 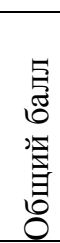 \\
\hline & & \multicolumn{8}{|c|}{ в баллах } \\
\hline Азаметли -95(стандарт) & 550 & 4,0 & 5 & 5 & 5 & 5 & 5 & 5 & 4,8 \\
\hline Гырмызы гюль-1 (стан) & 600 & 4,6 & 5 & 5 & 5 & 5 & 5 & 5 & 4,9 \\
\hline
\end{tabular}

С целью определения влияния натуральных добавок, и их дозировки на процесс брожения и кислотонакопления, при замесе теста дошаб из хурмы вносили в дозировках: 5, 10 и 15\% к массе муки.

Подъемная сила хлебопекарных дрожжей с добавлением дошаба усилилась с повышением процентного его содержания. Наилучшими вариантами повышения подъемной силы и ускорения процесса созревания теста, является использование дошаба в количестве 5 и $10 \%$ к массе муки, но с точки зрения функциональности была принята дозировка $10 \%$.

Хлебобулочные изделия с добавлением дошаба, в сравнении со стандартом имели лучший удельный объем и пористость мякиша
[5]. Влажность в процессе хранения хлебобулочных изделий практически не изменялась. $\mathrm{C}$ точки зрения полезности хлебобулочных изделий и использования их в качестве профилактического средства для групп населения, работающих и проживающих в зонах с экологически неблагоприятной обстановкой, они необходимы [6]. Целесообразно было изучить, как изменяются свойства теста и качество готовых изделий в зависимости от количества вносимой добавки.

Свойства хлеба, полученного из предлагаемой композиции для хлебобулочных изделий из пшеничной муки, приготовленного опарным способом, сведены в таблицу 5. 


\begin{tabular}{|c|c|c|c|c|c|c|}
\hline Impact Factor: & $\begin{array}{l}\text { ISRA (India) } \\
\text { ISI (Dubai, UAE } \\
\text { GIF (Australia) } \\
\text { JIF }\end{array}$ & $\begin{array}{r}=1.344 \\
=0.829 \\
=0.564 \\
=1.500\end{array}$ & $\begin{array}{l}\text { SIS (USA) } \\
\text { PИНЦ (Russia) } \\
\text { ESJI (KZ) } \\
\text { SJIF (Morocco) }\end{array}$ & $\begin{array}{l}=0.912 \\
=\mathbf{0 . 2 0 7} \\
=\mathbf{3 . 8 6 0} \\
=\mathbf{2 . 0 3 1}\end{array}$ & $\begin{array}{l}\text { ICV (Poland) } \\
\text { PIF (India) } \\
\text { IBI (India) }\end{array}$ & $\begin{array}{l}=6.630 \\
=1.940 \\
=4.260\end{array}$ \\
\hline
\end{tabular}

Хлебопекарные качества зерна с добавлением дошаба из хурмы

Таблица 5.

\begin{tabular}{|c|c|c|c|c|c|c|c|c|c|}
\hline \multirow[t]{2}{*}{$\frac{\pi}{0}$} & \multirow[t]{2}{*}{ 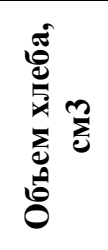 } & 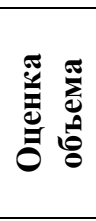 & 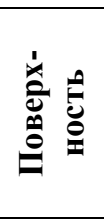 & $\frac{\tilde{a}}{\hat{a}}$ & 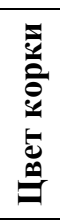 & 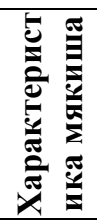 & 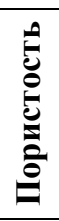 & 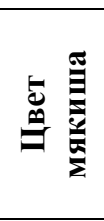 & 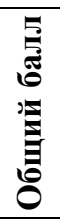 \\
\hline & & \multicolumn{8}{|c|}{ в баллах } \\
\hline \multicolumn{10}{|l|}{ Азаметли 95} \\
\hline + 5\% дошаб из хурмы & 620 & 4,6 & 5 & 5 & 5 & 5 & 5 & 3 & 5,4 \\
\hline$+10 \%$ & 610 & 4,6 & 5 & 5 & 5 & 5 & 5 & 1 & 5,1 \\
\hline$+15 \%$ & 600 & 4,6 & 5 & 5 & 5 & 3 & 4 & 1 & 4,9 \\
\hline \multicolumn{10}{|l|}{ Гырмызы гюль } \\
\hline$+5 \%$ дошаб из хурмы & 550 & 4,0 & 5 & 5 & 5 & 5 & 4 & 3 & 4,4 \\
\hline$+10 \%$ & 600 & 4,6 & 5 & 5 & 5 & 5 & 3 & 1 & 4,0 \\
\hline$+15 \%$ & 500 & 3,3 & 5 & 5 & 5 & 4 & 4 & 1 & 3,9 \\
\hline
\end{tabular}

Результаты исследований показали, что хорошими показателями отличалась проба хлеба, приготовленная с внесением дошаба из хурмы в количестве 5 и 10\% к массе муки (Азаметли - 95). Формоустойчивость, удельный объем и пористость данного образца хлеба увеличивались по сравнению со стандартом. Внесение добавки в количестве $15 \%$ к массе муки ухудшало некоторые органолептические показатели готовых хлебобулочных изделий, а именно наблюдалось сильное потемнение мякиша, но он становится более мягким, разрыхленным, а также появлялся приятный сладковатый привкус.

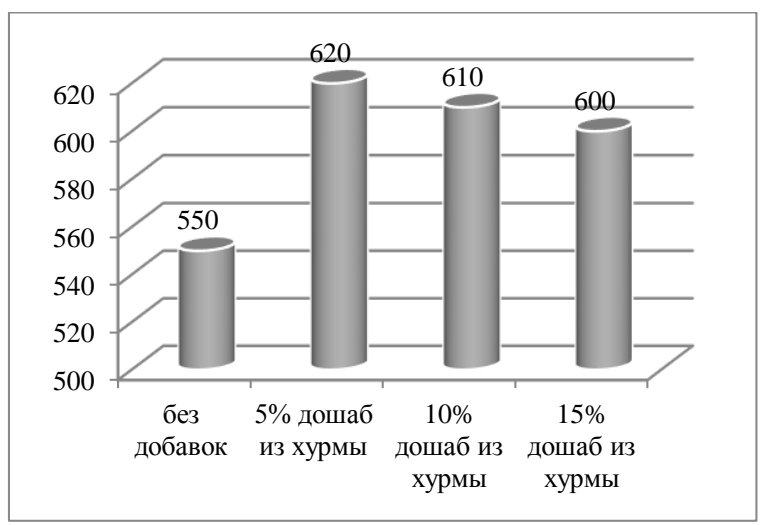

Рисунок 1 - Объем хлеба из муки сорта «Азаметли 95», см3

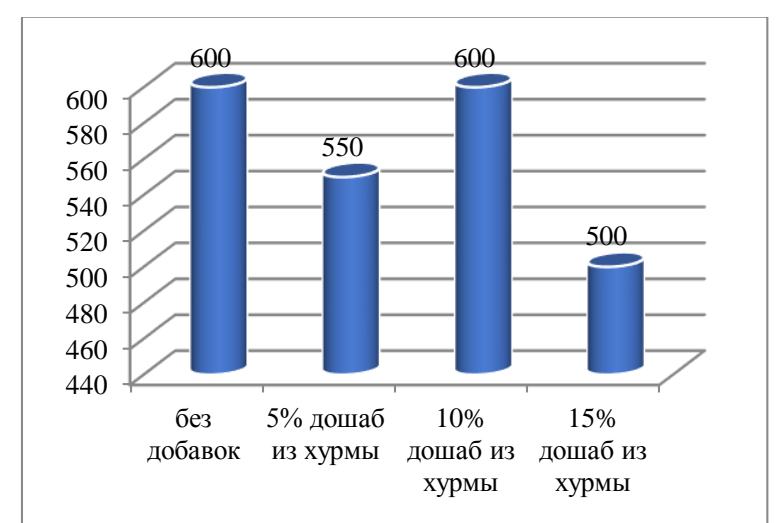

Рисунок 2 - Объем хлеба из муки сорта «Гырмызы гюль», см3 


\begin{tabular}{|c|c|c|c|c|c|c|}
\hline Impact Factor: & $\begin{array}{l}\text { ISRA (India) } \\
\text { ISI (Dubai, UAE } \\
\text { GIF (Australia) } \\
\text { JIF }\end{array}$ & $\begin{array}{r}=1.344 \\
=0.829 \\
=0.564 \\
=1.500\end{array}$ & $\begin{array}{l}\text { SIS (USA) } \\
\text { PИНЦ (Russia) } \\
\text { ESJI (KZ) } \\
\text { SJIF (Morocco) }\end{array}$ & $\begin{array}{l}=0.912 \\
=0.207 \\
=\mathbf{3 . 8 6 0} \\
=\mathbf{2 . 0 3 1}\end{array}$ & $\begin{array}{l}\text { ICV (Poland) } \\
\text { PIF (India) } \\
\text { IBI (India) }\end{array}$ & $\begin{array}{l}=6.630 \\
=1.940 \\
=4.260\end{array}$ \\
\hline
\end{tabular}

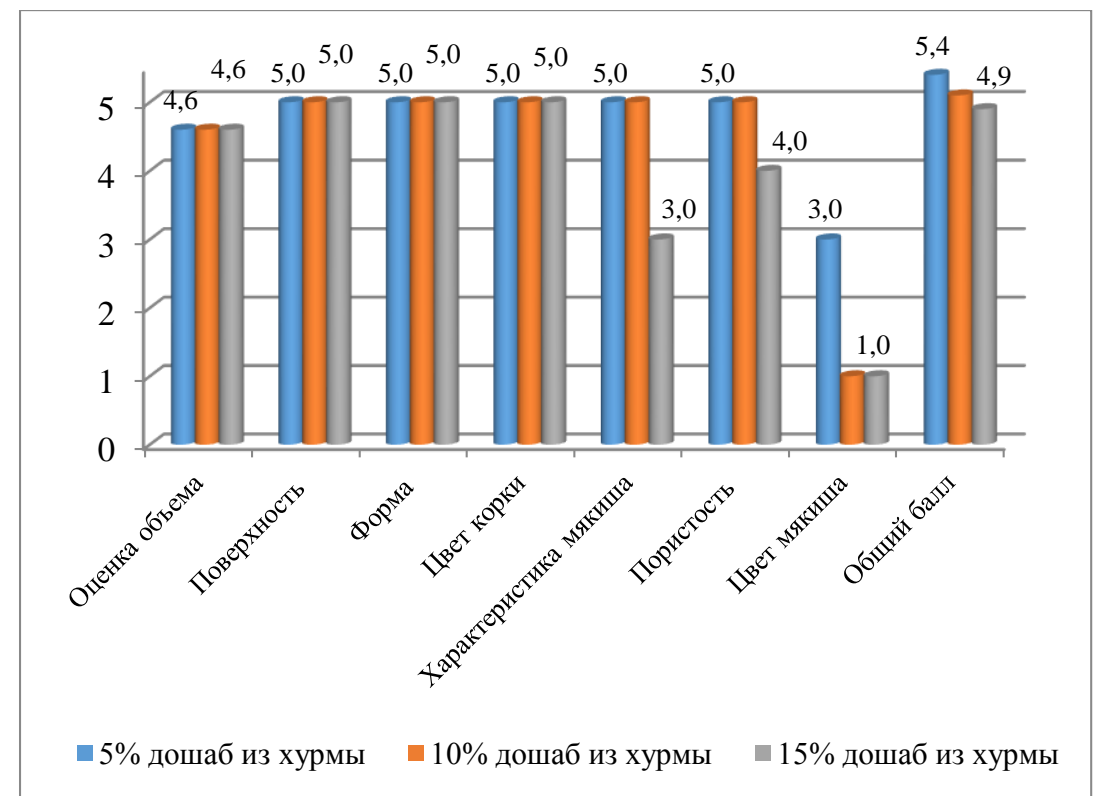

Рисунок 3 - Другие характеристики хлеба из муки сорта "Азаметли 95", в баллах

Результаты исследования влияния натуральной добавки на свойства теста показали, что кислотность хлеба с внесением добавки в исследуемых дозах увеличивалась.

Таблица 6.

Кислотность хлеба с добавлением дошаба из хурмы

\begin{tabular}{|l|l|l|}
\hline$№$ & Наименование хлеба & Кислотность в градусах \\
\hline 1 & Азаметли 95+ 5\% дошаб из хурмы & 2,6 \\
\hline 2 & $+10 \%$ дошаб из хурмы & 3,2 \\
\hline 3 & $+15 \%$ дошаб из хурмы & 3,6 \\
\hline 4 & Гырмызы гюль+ 5\% дошаб из хурмы & 2,2 \\
\hline 5 & $+10 \%$ дошаб из хурмы & 2,4 \\
\hline 6 & $+15 \%$ дошаб из хурмы & 3,0 \\
\hline
\end{tabular}

\section{Показатели увеличения объема хлеба по сравнению со стандартом}

Таблица 7.

\begin{tabular}{|l|l|}
\hline Наименование хлеба & Увеличение объема в \% \\
\hline Азаметли 95+ 5\% дошаб из хурмы & $+12,7$ \\
\hline$+10 \%$ дошаб из хурмы & $+10,9$ \\
\hline$+15 \%$ дошаб из хурмы & $+9,0$ \\
\hline Гырмызы гюль+ 5\% дошаб из хурмы & $-8,3$ \\
\hline$+10 \%$ дошаб из хурмы & 0 \\
\hline$+15 \%$ дошаб из хурмы & $-16,6$ \\
\hline
\end{tabular}

При введении добавок в рецептуру хлеба в количестве 5 - $10 \%$ к массе основного сырья обеспечивается увеличение продолжительности хранения готовой продукции без плесневения, а также предотвращением черствения хлеба [7].

Использование добавок позволяет сократить длительность процесса брожения теста, улучшить газообразование, повысить качество готовой продукции, которое заключается в улучшении пористости хлеба, и придает специфический вкус, аромат и профилактические свойства. А также позволяет достичь ускорения процесса созревания теста по сравнению со стандартом, ускорения процесса расстойки тестовых заготовок, ускорения процесса выпечки, увеличения срока хранения хлеба, улучшения реологических свойств теста; увеличение формоустойчивости тестовой заготовки при брожении, отсутствие эффекта расплывчатости, снижение комковатости мякиша, повышение 
активности работы дрожжей за счёт обеспечения необходимым для жизнедеятельности количества сахаров.

Уменьшение эксплуатационных следующих расходов производственноскладываются из сокращение продолжительности технологического процесса, сокращение использования трудовых ресурсов, уменьшение расхода электроэнергии, снижение времени эксплуатации производственных помещений и коммунальных расходов.

\section{Conclusion}

Предлагаемая новая рецептура позволяет обогатить продукт функциональными ингредиентами, необходимыми для нормального функционирования организма человека, удлиняют срок сохранения свежести, а также эти хлебобулочные изделия можно рекомендовать как функциональный продукт питания для людей, проживающих в регионах с неблагополучной экологической обстановкой в качестве продукта детоксикационного назначения.

Хурма японская. Хурма обладает мочегонным действием и тонизирующими свойствами. Она улучшает аппетит, повышает работоспособность, успокаивает нервную систему укрепляет сердечно-сосудистую систему [8]. Содержащийся в хурме магний снижает вероятность образования камней в почках, а железо активно участвует в кровотворных процессах и препятствует развитию анемии. Обладает бактерицидным действием в отношении кишечной и сенной палочки, золотистого стафилококка. Благодаря высокому содержанию йода в хурме медики рекомендуют ее для профилактики и при начальных стадиях заболеваний щитовидки. Ягода обладает великолепным антибактериальным воздействием. Врачи рекомендуют употреблять хурму при панкреатите [9].

Белки - 0,5 г, углеводы - 15,3 г, жиры - 0,4 $\Gamma$, органические кислоты - 0,1 г, пищевые волокна - 1,6 г, вода - 81, 5 г. дисахариды, моносахариды - 15,3 г, жирные кислоты (насыщенные) - 0,1 г, зола - 0,6 г. Наравне с моносахаридами в ней также имеются витамины (B1, В2, В6, С, Р, РР и др.), фенольные соединения (катехины, лейкоантоцианы, флаваноиды и др. ), азотистые соединения (аминокислоты, полипептиды, белки и др.) макроэлементы (натрий, калий, кальций, железо, медь, марганец, йод, бром и др.). и богата другими элементами [10].

Дошаб получают путём выжимания из из японской хурмы японской хурмы сока и выпаривания. Его применяют при малокровии у ослабленных больных, при гиповитаминозах С и A, катарах верхних дыхательных путей, как отхаркивающее средство.

\section{References:}

1. Troyanova T.L. (2005) Razrabotka tekhnologii pishchevyh dobavok iz rastitel'nogo syr'ya. Diss. kand. tekh. nauk. Krasnodar. 2005. - 144 p.

2. Goroshchenko L. (2006) Hleb i hlebobulochnye izdeliya // Prodovol'stvennyj biznes. - 2006.№ 8 .

3. Shepelev A.F., Kozhuhova O.I., Turov A.S. (2001) Tovarovedenie i ehkspertiza zernomuchnyh tovarov. Mart. Rostov na Donu 2001.

4. (2012) Tovarovedenie i ehkspertiza prodovol'stvennyh tovarov. pod red V.I.Krishtafovich. Laboratornyj praktikum M.

5. (2004) Tovarovedenie zernomuchnyh i konditerskih tovarov: Uchebnik dlya vuzov/ N.A. Smirnova, L.A. Nadezhnova. - M.: EHkonomika.
6. Ahmedov A.I., Kurbanova A.A. (2010) Azerbajdzhanskij hleb. «Gyandzhlik», Baku.

7. Ivanova T.N. (2005) Biologicheski aktivnye dobavki i ih primenenie: uchebnoe posobie. Orel GTU.

8. Ahundov F.G. (1998) Tovarovedenie, hranenie i pererabotka plodov i ovoshchej. Baku, 1998. $140 \mathrm{p}$.

9. Bumba G.CH. (1970) Himicheskij sostav plodov vostochnoj hurmy i ih dieticheskoe znachenie. Sbornik nauchnyh trudov aspirantov i molodyh nauchnyh sotrudnikov. Moscow, VNII rastenevodstva.

10. Dostiyari EH. N., Nabiev A.A. (2011) Issledovanie tekhnologii proizvodstva shirokogo assortimenta pishchevyh produktov iz plodov hurmy. Monografiya. Baku, «Elm», $180 \mathrm{p}$. 